\title{
Infection following fractures of the proximal tibia - a systematic review of incidence and outcome
}

\author{
Ralf Henkelmann ${ }^{1}$, Karl-Heinz Frosch², Richard Glaab ${ }^{3}$, Helmut Lill ${ }^{4}$, Christian Schoepp ${ }^{5}$, Dominik Seybold ${ }^{6}$, \\ Christoph Josten ${ }^{1}$, Pierre Hepp ${ }^{1 *}$ and Committee TRAUMA of the AGA-Society for Arthroscopy and Joint Surgery
}

\begin{abstract}
Background: To systematically review all available studies of operatively treated proximal tibia fractures and to report the incidence of superficial or deep infection and subsequent outcomes.
\end{abstract}

Methods: A systematic review of the literature in Medline, Cochrane, Embase and GoogleScholar was conducted to identify studies with cohorts of patients with infection after surgical treatment of proximal tibia fractures. Studies were included according to predefined inclusion and exclusion criteria. The studies were analysed for methodological deficiencies and quality of outcome reporting based on the Level of Evidence (LOE) and Coleman Methodology Scoring (CMS.)

Results: In total 32 studies were included. There was heterogeneity between the studies, in terms of subject of the studies, outcome criteria, fracture type and classification, surgical techniques and length of follow-up. Therefore, no meta-analysis could be performed. The average CMS was 54.2 (range 36-75). The included studies were 25 case series (LOE IV), 6 were prospective cohort studies (LOE III) and one was a prospective randomized trial (LOE I). 203 (12.3\%, range: $2.6-45.0 \%)$ infections occurred in the overall population $(n=2063)$. Those were divided into 129 deep infections and 74 superficial infections. Revision due to infection was reported in 29 studies, microbiological results in 6, respectively. 72 (55,8\%) of 129 cases reporting outcome after deep infection had an unsatisfactory outcome with substantial limitations of the affected joint and leg.

Conclusions: Postoperative infections are a challenge, sometimes requiring several revisions and often with a worse outcome. Further studies with structured study protocols should be performed for a better understanding of risk factors to improve treatment outcomes.

Keywords: Surgical site infection, Outcome after infection, Proximal tibia fracture, Tibia plateau fracture, Outcome after infection

\section{Background}

Proximal tibial fractures are common trauma injuries. Their severity is defined by fracture morphology and associated soft tissue injury. Management is challenging and patients are at risk for adverse outcomes [1].

In current literature, postoperative rates of surgical site infections (SSI) are between 3 and 45\% [2-4]. This rate is high compared to SSIs with a rate of $2-3 \%$ of other

\footnotetext{
* Correspondence: pierre.hepp@medizin.uni-leipzig.de

1 Department of Orthopedics, Trauma and Plastic Surgery, University of Leipzig, Liebigstr. 20, 04103 Leipzig, Germany

Full list of author information is available at the end of the article
}

fractures treated with open reduction and internal fixation (ORIF) [5-7] Why patients with proximal tibial fractures are prone to SSI compared to other fractures is unclear.

Furthermore, a change of the microbiological spectrum with regard to bacterial types and antibiotic resistance has been reported $[8,9]$. Concomitant soft tissue injuries and open fractures complicate treatment through frequent operative revisions and higher infection rates.

Postoperative infections are a feared complication with an often unsatisfying outcome for the patient and possible loss of function in the affected region [10]. Patients with SSI have a higher mortality rate compared with patients 
without SSI and an extended hospital stay $[11,12]$. To the authors' knowledge, no previous review on this topic has been performed.

The purpose of this systematic review was to gain a more comprehensive understanding of the current infection rate and the outcome after infection of surgically treated proximal tibia fractures. Furthermore reoperation rates and if reported microbiology smears should be analysed.

\section{Methods}

This systematic review followed the PRISMA (Preferred Reporting Items for Systematic Reviews and Meta- Analyses) guidelines for reporting systematic reviews and meta-analyses and the Cochrane Handbook for Systematic Reviews of Interventions. No review protocol was established prior to the begin of the search [13-15].

In February 2016 a systematic search in Medline (www.pubmed.com), Cochrane Library (www.cochranelibrary.com) and EMBASE using the following search terms and their combination with AND/OR: tibia* plateau fracture, proximal tibia fracture, tibia* head fractures, tibia head, knee, proximal tibia, infection, surgical site infection, surgical side infection, outcome, follow up and review was performed. The search included all available studies until the day of the search. Furthermore Reviews, editorials and opinion articles were used as potential sources of further references. The search strategy in Medline is pictured in Table 1.

To include 'grey literature', a search in Google Scholar with the search 'tibial plateau fracture AND infection AND outcome,' 'tibia head fracture AND infection AND outcome' and 'proximal tibia fracture AND infection AND outcome' was performed.

Studies were included if they met the following criteria: (1) English or German language, (2) patients with tibial plateau fracture or tibial plateau fractures separable in the body of the text or in tables of any classification; (3) reported rate of SSI and outcome (4) studies with LOE of I through IV. Studies were excluded if they met one of the following criteria: (1) inclusion criteria were not met; (2) patients with tibia shaft fractures; (3) basic science only; (4) animal model only; (5) editorial, opinion, case report with less than ten patients, review or commentary.

Two authors ( $\mathrm{RH}$ and $\mathrm{PH}$ ) independently screened all retrieved items by tittle and abstract, than full text as necessary using the pre-determined selection criteria. Disagreements were resolved through discussion with CJ.

Data on study characteristics and design, level of evidence (LOE), demographic parameters, classification, surgical technique, infections, microbiology, revision surgeries, clinical follow-up and treatment outcomes were extracted by a single author $(\mathrm{RH})$ from studies in a spreadsheet.
Table 1 Pubmed.com search dated 2016.02.26

\begin{tabular}{|c|c|c|}
\hline step & search terms & hits \\
\hline$\# 1$ & proximal tibia fracture & 2082 \\
\hline \#2 & tibia* head fractures & 552 \\
\hline \#3 & \#1 AND infection & 313 \\
\hline \#4 & \#3 AND outcome & 137 \\
\hline \#5 & \#2 AND infection & 58 \\
\hline \#6 & \#2 AND outcome & 84 \\
\hline \#7 & $\# 1$ "review" & 216 \\
\hline \#8 & \#2 "review" & 57 \\
\hline \#9 & knee AND infection & 9471 \\
\hline \#10 & knee AND surgical site infection & 1603 \\
\hline \#11 & knee AND surgical side infection & 138 \\
\hline \#12 & knee AND surgical site infection AND outcome & 456 \\
\hline \#13 & \#12 AND fracture & 99 \\
\hline \#14 & proximal tibia & 6655 \\
\hline \#15 & \#14 AND infection & 556 \\
\hline \#16 & \#15 AND outcome & 209 \\
\hline \#17 & \#15 AND follow up & 237 \\
\hline \#18 & tibia head & 1131 \\
\hline \#19 & \#18 AND infection & 157 \\
\hline \#20 & tibia* plateau fracture & 1355 \\
\hline \#21 & \#20 AND infection & 181 \\
\hline \#22 & \#20 AND outcome & 444 \\
\hline \#23 & \#20 AND outcome AND infection & 107 \\
\hline
\end{tabular}

Statistical analysis was performed using the Statistical Package for Social Sciences (SPSS) v. 20 for Windows or RevMan v 5.3 (Nordic Cochrane Centre, Copenhagen, Denmark). All values are expressed as mean \pm standard error of the mean (SEM) or range from minimum to maximum. If possible data will be pooled, an analysis of heterogeneity will be performed and a meta-analysis will be done. Furthermore this will be pictured in forest plots if possible.

\section{Coleman methodology scoring (CMS)}

In addition to evaluating the studies for variables of interest, we also analyzed these studies for methodological deficiencies and quality of outcome reporting based on the recommendations given by Coleman et al. The score has ten sections with a maximum of 100 points [16].

\section{Outcome measures}

The primary outcomes evaluated in this review were the rate of infection and the functional outcome after infection. The infections were graded into deep (DI) and superficial infections (SI) as classified in the articles. Secondary outcomes were results of microbiology smears and rate of reoperations. 


\section{Results}

\section{Included studies}

A total of 839 titles and abstracts of articles were screened (Fig. 1). According to our inclusion and exclusion criteria and after removal of duplicates, 32 articles (2063 patients, Table 2) were included for this review. The study of Heppert et al. was excluded for this analysis due to the fact that their main inclusion criteria was a postoperative infection and their data would bias our results.

Of all included studies, 25 were case series (LOE IV), 6 were prospective cohort studies (LOE III) and one was a prospective randomized trial (LOE I). The average CMS was 54.2 (range 36-75) points.

Fractures were classified in descending order according to $\mathrm{AO}$ (59.4\%), Schatzker (34.4\%) and not mentioned/other in the article (6.3\%).

\section{Open fractures}

In total, if specified in the articles ( $n=24,1329$ patients), $22.9 \%$ open fractures $(n=304)$ and $77.1 \%$ closed fractures (1024) were within the study population in those studies.

\section{Infections}

Two hundred three (9.8\%, range: $2.6-45.0 \%)$ infections occurred in the overall population $(n=2063)$. Those were divided into 129 deep infections and 74 superficial infections.

Studies without open fractures ( $n=8,734$ patients) had an infection rate of $10.3 \%(3.1-18.8 ; 39 \mathrm{DI}, 13 \mathrm{SI})$. Studies which included open fractures $(n=24,1329$ patients) resulted in an infection rate of $12.9 \%$ (2.6-45.0; 90 DI, 61 SI).

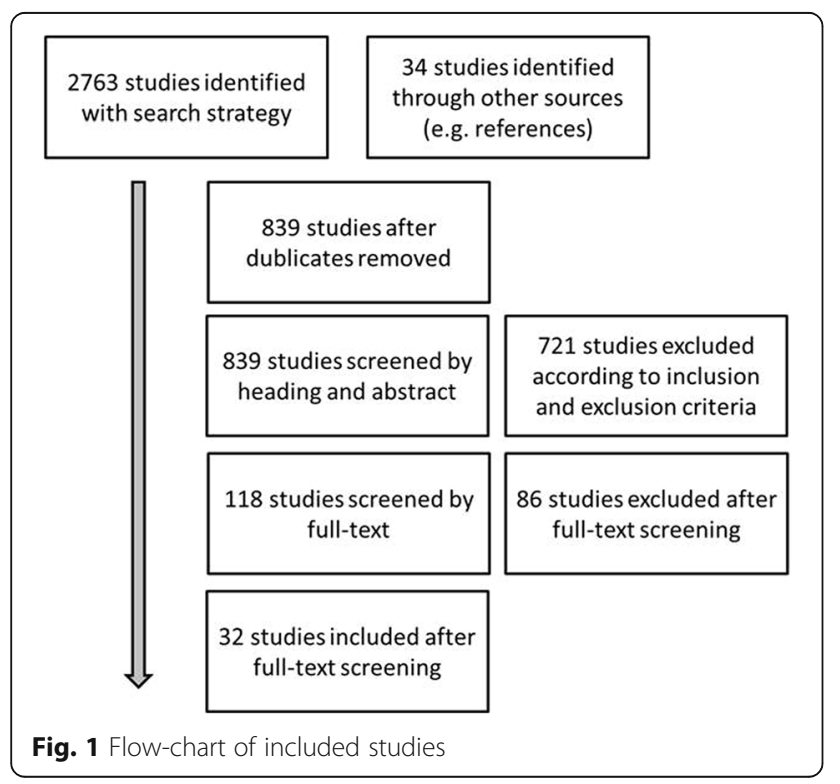

\section{Reoperation due to infection}

In 29 studies, a reoperation due to infection was reported. Those studies had an average infection rate of $11.9 \%$ (2.6-45.0) and in total 192 infections within their study populations (129 DI, $63 \mathrm{SI})$. In those studies an average reoperation rate until the end of their follow-up between 2.1 and 5 reoperations per patient was reported.

\section{Microbiology}

In six studies positive results of microbiological smears were reported. The most common bacterium was Staphylococcus aureus with or without resistance (methicillin-resistant Staphylococcus aureus, MRSA), followed by Enterobacter or Enterococcus species (Tables 2 and 3).

\section{Studies with outcome information}

Information about the outcome after infection was given in all included studies (Table 2) with 2063 patients (18.6\% open fractures, range 0-100\%). 203 infections (12.3\% (2.6-45.0) occurred in this population including 129 (63.5\%) deep infections. All patients with superficial wound infections $(n=74)$, were treated with wound care, oral antibiotics or single debridement if necessary. Furthermore three studies of those had no DI in their study population. All reported SI were reported with a good outcome withouth further specification.

In summary, $72(55,8 \%)$ of 129 cases reporting outcome after deep infection had an unsatisfactory outcome with substantial limitations of the affected joint and leg. The most common limitation was non-union or pseduarthrosis (15.3\%). Followed by joint stiffness due to operation (arthrodesis $7.8 \%$ ), ankylosis $(9.3 \%)$ or not specified sitffness (1.6\%). The worst case an amputation was reported in $5.4 \%$ (Table 4 ).

\section{Discussion}

This systematic review of the literature on infections after surgical treatment of proximal tibia fractures included 32 studies and a total of 2063 patients. To our knowledge, this is the first review dealing with this topic.

Only one study investigated the outcome of infection after proximal tibia fractures [10]. Eighteen years ago, Heppert et al. included 52 patients with a mean age of 51.5 (18-89) years and a follow up between 11 and 13 months. Due to the infection 263 reoperation procedures (mean of 5.1 reoperations per patient) were performed. The individual outcome was an axial deformity $(n=15)$, ankylosis $(n=$ $2)$, arthrodesis $(n=10)$ and amputation $(n=9)$. Hence they had a poor outcome in $69.2 \%(n=36)$. In the present review we could extract 129 patients from 32 studies with further information concerning treatment outcome after postoperative infection. 72 patients $(55.9 \%)$ had severe limitations and thus a poor outcome (Table 2). 


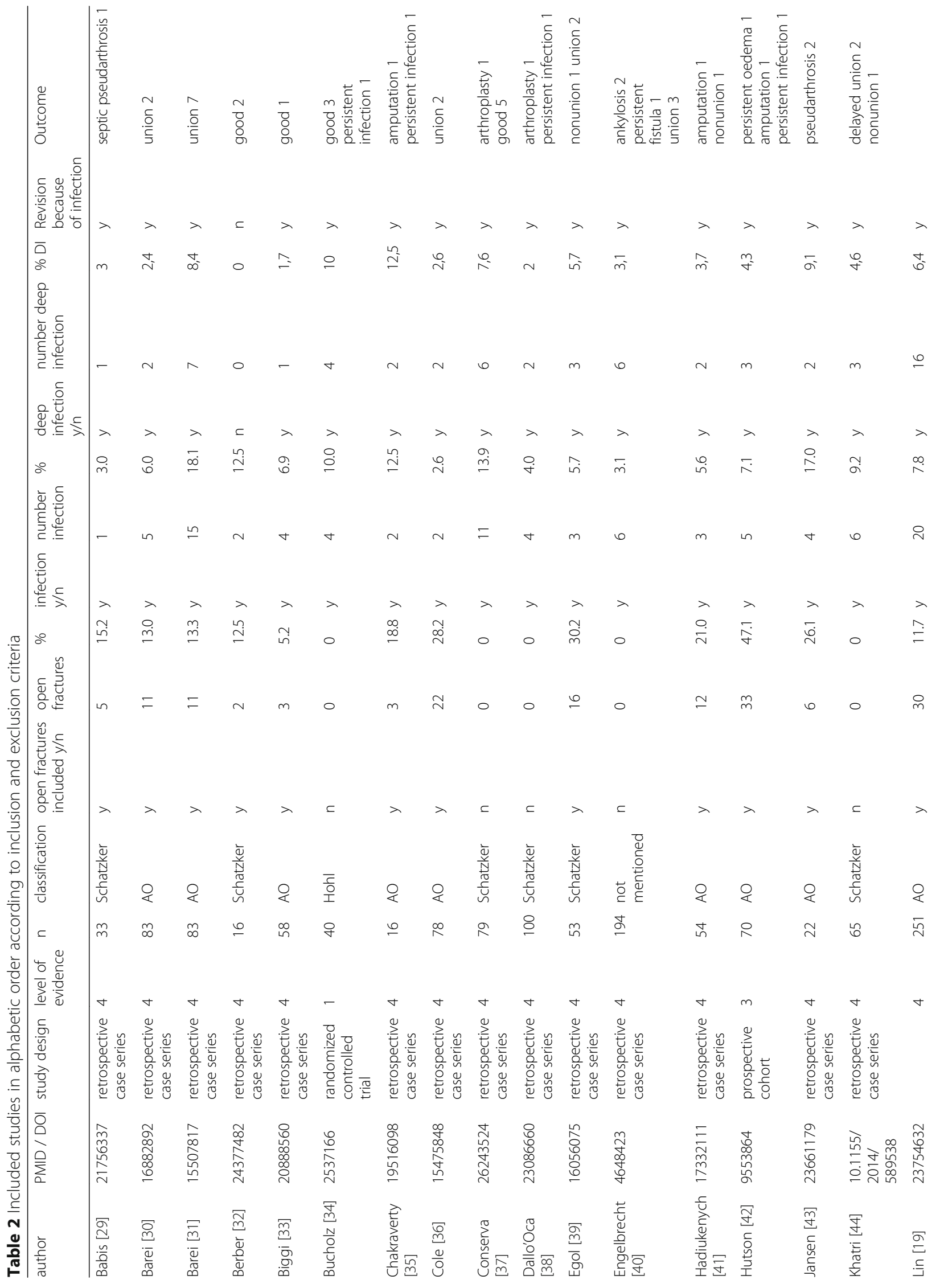




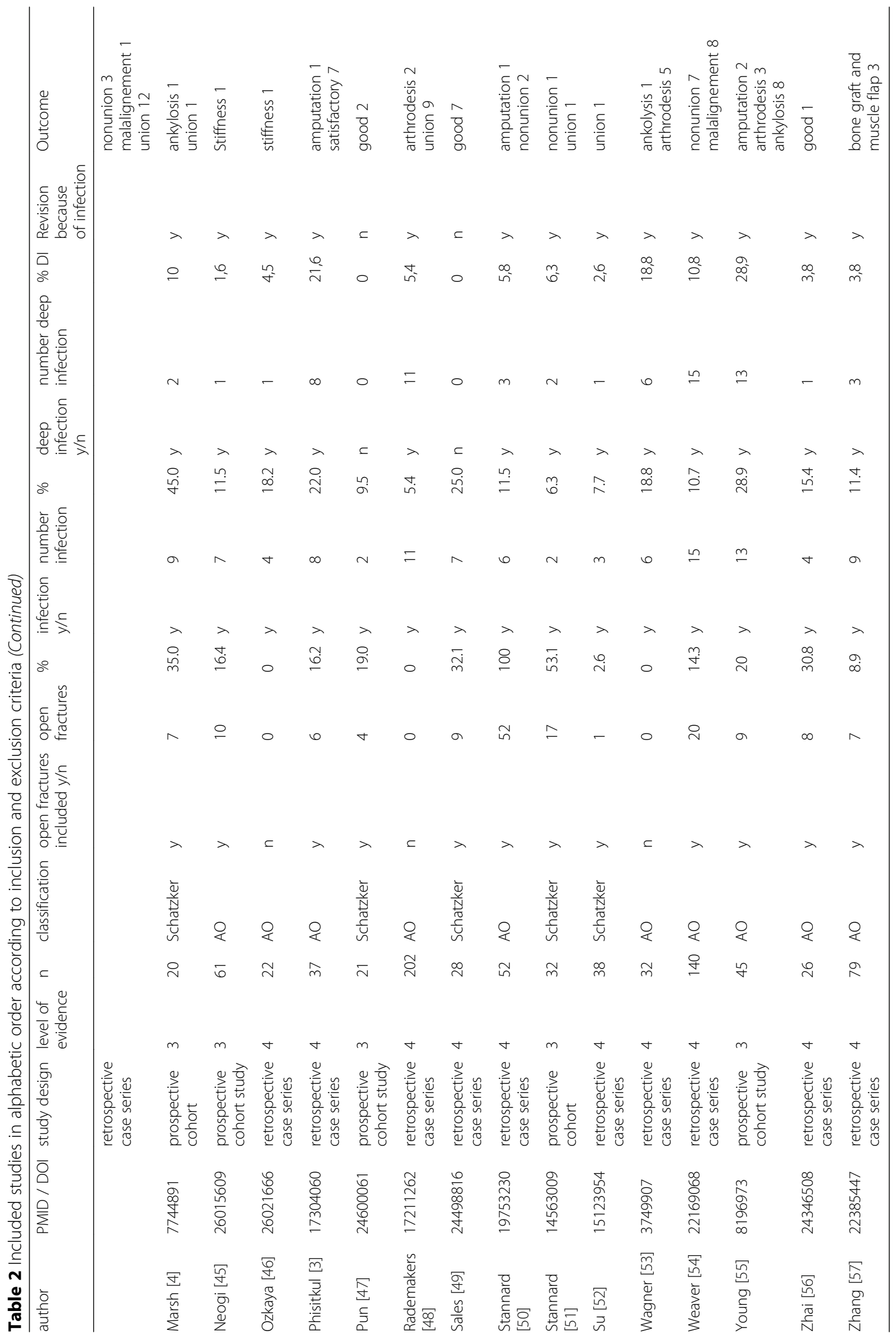


Table 3 Results of microbiological smears were given in six studies

\begin{tabular}{|c|c|c|c|c|c|c|}
\hline & Engelbrecht [40] & Lin [19] & Marsh [4] & Cole [36] & Phisitkul [3] & Barei [31] \\
\hline Staphylococcus aureus & $x$ & $x$ & $x$ & & $x$ & $x$ \\
\hline MRSA & & $x$ & & $x$ & $x$ & $x$ \\
\hline Staphylococcus epidermidis & & $x$ & & & $x$ & \\
\hline Streptococcus & & $x$ & & & & \\
\hline Pseudomonas aeruginosa & & $x$ & & & & \\
\hline Enterococcus & & $x$ & & & $x$ & $x$ \\
\hline Enterobacteriaceae & & $x$ & & & $x$ & $x$ \\
\hline Haemophilus influenzae & & & & & $x$ & \\
\hline no growth (if reported) & & $x$ & & $x$ & $x$ & \\
\hline
\end{tabular}

Many studies are available concerning proximal tibia fractures. Literature reports a wide range of infection rates between $2.6-45 \%$. The present review summarizes an infection rate of $12.3 \%$. It is well known that infection rates are high for those fractures compared to an infection rate of $2-3 \%$ of other fractures treated with open reduction and internal fixation (ORIF) [5-7].

The most common bacterium was Staph. aureus with or without resistance (MRSA), followed by Pseudomonas, Staph. epidermidis, Enterobacteriaceae or Enterococcus species. The bacterial spectrum corresponded with the incidence in the literature [8]. In the face of a changing bacterial spectrum and increasing resistances a change of the current prophylactic antibiotic regimen could potentially close gaps. In particular the change of the bacterial spectrum in proximal tibia fractures was decribed by Morris et al [17].

Operative time and open fractures are independent predictors of postoperative infections $[18,19]$. In the current study we could confirm a higher infection rate in studies which included open fractures. Nevertheless,

Table 4 Outcome of 129 patients with DI

\begin{tabular}{lll}
\hline & Number & Percent \\
\hline amputation & 7 & 5.4 \\
ankylosis & 12 & 9.3 \\
stiffness & 2 & 1.6 \\
persistent oedema & 1 & 0.8 \\
arthrodesis & 10 & 7.8 \\
malalignement & 9 & 7.0 \\
non-union / pseudarthrosis & 20 & 15.3 \\
persistent infection / septic pseudarthrosis & 5 & 3.9 \\
persistent fistula & 1 & 0.8 \\
arthroplasty & 2 & 1.6 \\
muscle flap & 3 & 2.3 \\
union / good / satisfactory & 57 & 44.2 \\
total patients & 129 & 100 \\
\hline
\end{tabular}

little information regarding management of postoperative infections in tibial plateau fractures and their treatment outcome has been reported.

Fractures of the tibial plateau are usually severe injuries and include a wide variety of fracture patterns. The choice of approach is dictated principally by the fracture pattern, with consideration of the soft tissue envelope, patient factors, and associated injuries [20]. Due to the trauma mechanism, high energy trauma in young and direct impact in elderly patients, the soft tissue is usually traumatized twice, by the accident and sometimes by the subsequent operation. Accordingly, the rate of complications after fracture stabilization is high [21, 22]. In particular, the combination of fracture and soft tissue damage is challenging. Even without infection the functional outcome may be poor [23]. Limited range of motion and progressive osteoarthritis are possible complications which occur in $26.4 \%$ according to a recent study [24]. Infections even worsen the situation. Postoperative deep infections of the tibial plateau ended in most of the cases with a considerable functional loss.

\section{Limitations and future perspectives}

One major limitation of the current review is the obvious heterogeneity between the studies, in terms of subject of the studies, outcome criteria, fracture type and classification, surgical techniques and length of follow-up. Moreover this was evident by the weak CMS of the included studies. The basic limitation of pooling data is the fact that a surgical site infection is a recorded side effect and not a subject of the included studies. Therefore, a meta-analysis with weighting of the studies or a determination of odds ratio of possible risk factors could not be performed. A pooling of reported percentage SSI rates in the studies could be done according to a narrative analysis.

If an infection occurred, inconsistent information with regard to time span until operation, number of reoperations, results of microbiological smears, treatment strategy and clinical outcome described by ROM or validated score could be retrieved. Furthermore it was seldom possible to 
comprehend if the infection occurred in an open or closed fracture. Also the degree of soft-tissue damage was seldom documented.

The limitations of the review provide guidance that could be used for future studies. Outcome was reported very inconsistently with different scores or range of motion. A few studies used an instrument to measure quality of life like SF-36 (36-item Short-Form General Health Survey) or KOOS. We would recommend giving detailed information about each patient with regard to comorbidities, long-term medication, time-span until operation, surgery duration, blood loss, and postoperative treatment protocol. Furthermore, risk factors for postoperative infections were characterized as describing reduced fitness, patient frailty and surgery complexity $[25,26]$. We would also recommend a score which measures quality of life and function in daily living like SF36 or KOOS $[27,28]$. The KOOS is a patient-reported outcome measurement instrument. It is widely used in clinical trials and its psychometric properties have been validated. The score consists of five separately scored and validated subscales: KOOS Pain, KOOS Symptoms, Function in daily living (KOOS ADL), Function in Sport and Recreation (KOOS Sport/Rec), and knee-related Quality of Life (KOOS QOL). Additionally, in cases of infection, the involved bacterium, number of reoperations and detailed treatment strategy should be stated. This approach could provide independent entry points which could be positively influenced to reduce SSIs. The pooled review data are too weak to state a precise treatment algorithm for future patients.

\section{Conclusion}

This review proved that in literature over all included studies infection rates of tibial plateau fractures are 4 to 5 fold higher than other fractures which were treated with ORIF. Furthermore reported outcome of patients with DI had considerable limitations of their affected leg. This review with It pointed out that there is still a lack in the treatment of tibial plateau fractures to prevent such high rates of SSI.

\section{Abbreviations \\ AO: Arbeitsgemeinschaft für Osteosynthesefragen; CMS: Coleman Methodology Scoring; DI: Deep Infection; KOOS: Knee injury and Osteoarthritis Outcome Score; LOE: Level of Evidence; MRSA: methicillin- resistant Staphylococcus aureus; ORIF: Open Reduction and Internal Fixation; PRISMA: Preferred Reporting Items for Systematic Reviews and Meta- Analyses; ROM: Range of Motion; SF-36: 36-item Short-Form General Health Survey; SI: Superficial Infection; SPSS: Statistical Package for Social Sciences; SSI: Surgical Site Infection}

\section{Acknowledgements}

We thank Dr. Jeremy Somerson for proof reading of the manuscript.

Funding

There was no funding for this work.

\section{Availability of data and materials}

All relevant data and studies are provided in an additional supporting file (supplemental). If further data were required they can be given by request to the author.

\section{Authors' contributions \\ $\mathrm{RH}$ and $\mathrm{PH}$ included or excluded studies, $\mathrm{RH}$ extracted data of included studies, RH and PH drafted the manuscript, KF, RG and $\mathrm{HL}$ developed the search strategy and helped to draft the manuscript. DS and CS participated in the development of the search strategy and performed the statistical analysis. CJ solved disagreement of $\mathrm{RH}$ and $\mathrm{PH}$ concerning including or excluding of studies and also helped to draft the manuscript. All authors read and approved the final manuscript.}

Ethics approval and consent to participate

Not applicable.

\section{Consent for publication}

Not applicable.

\section{Competing interests}

All authors declare no financial and personal relationships with other people or organizations that could potentially and inappropriately influence (bias) their work and conclusions. The authors declare that they have no competing interests.

\section{Publisher's Note}

Springer Nature remains neutral with regard to jurisdictional claims in published maps and institutional affiliations.

\section{Author details}

1'Department of Orthopedics, Trauma and Plastic Surgery, University of Leipzig, Liebigstr. 20, 04103 Leipzig, Germany. ${ }^{2}$ Department of Trauma and Reconstructive Surgery with Divion of Knee and Shoulder Surgery, Sports Traumatology, Asklepios Clinic St. Georg, Lohmühlenstr. 5, 20099 Hamburg, Germany. ${ }^{3}$ Departmet of Traumatology, Cantonal Hospital Aarau, Tellstrasse 25, CH-5001 Aarau, Switzerland. ${ }^{4}$ Department of Trauma and Reconstructive Surgery, DIAKOVERE Friederikenstift gGmbH, Humboldtstr. 5, 30169 Hannover, Germany. ${ }^{5}$ Departement of Orthopedic and Trauma Surgery, Berufsgenossenschaftliche Unfallklinik Duisburg, Großenbaumer Allee 250, 47249 Duisburg, Germany. 'Department of General and Trauma Surgery, University Bergmannsheil Bochum, Ruhr-University Bochum,

Bürkle-de-la-Camp-Platz 1, 44789 Bochum, Germany.

Received: 26 January 2017 Accepted: 14 November 2017

Published online: 21 November 2017

\section{References}

1. Choo KV, Morshed S. Postoperative complications after repair of tibial plateau fractures. The journal of knee surgery. 2014;27:11-9.

2. Barwick TW, Montgomery RJ. Knee arthrodesis with lengthening: experience of using llizarov techniques to salvage large asymmetric defects following infected peri-articular fractures. Injury. 2013;44:1043-8.

3. Phisitkul P, McKinley TO, Nepola JV, Marsh JL. Complications of locking plate fixation in complex proximal tibia injuries. J Orthop Trauma. 2007;21:83-91.

4. Marsh JL, Smith ST, Do TT. External fixation and limited internal fixation for complex fractures of the tibial plateau. J Bone Joint Surg Am. 1995;77:661-73.

5. Xu S, Mao Z, Liu B, Zhu H, Pan H. Evaluating the use of antibiotic prophylaxis during open reduction and internal fixation surgery in patients at low risk of surgical site infection. Injury. 2015;46:184-8.

6. Suzuki T, Morgan SJ, Smith WR, Stahel PF, Gillani SA, Hak DJ. Postoperative surgical site infection following acetabular fracture fixation. Injury. 2010;41: 396-9.

7. Ovaska MT, Mäkinen TJ, Madanat R, Huotari K, Vahlberg T, Hirvensalo E, Lindahl J. Risk factors for deep surgical site infection following operative treatment of ankle fractures. J Bone Joint Surg Am. 2013;95:348-53.

8. Cooper RA. Surgical site infections: epidemiology and microbiological aspects in trauma and orthopaedic surgery. Int Wound J. 2013;10(Suppl 1):3-8

9. Spellberg B, Guidos R, Gilbert D, Bradley J, Boucher HW, Scheld WM, Bartlett JG, Edwards J. The epidemic of antibiotic-resistant infections: a call to action for the medical community from the Infectious Diseases Society of America. 
Clinical infectious diseases: an official publication of the Infectious Diseases Society of America. 2008;46:155-64.

10. Heppert V, Rheinwalt $\mathrm{K}$, Winkler $\mathrm{H}$, Wentzensen A. Infection of the proximal tibia after fractures? An avoidable complication. Eur J Orthop Surg Traumatol. 1997;7:195-8.

11. Basques BA, Webb ML, Bohl DD, Golinvaux NS, Grauer JN. Adverse events, length of stay, and readmission after surgery for tibial plateau fractures. J Orthop Trauma. 2015;29:e121-6.

12. Kirkland KB, Briggs JP, Trivette SL, Wilkinson WE, Sexton DJ. The impact of surgical-site infections in the 1990s: attributable mortality, excess length of hospitalization, and extra costs. Infect Control Hosp Epidemiol. 1999;20:725-30.

13. Liberati A, Altman DG, Tetzlaff J, Mulrow C, Gøtzsche PC, loannidis JP, John PA, Clarke M, Devereaux PJ, Kleijnen J, Moher D. The PRISMA statement for reporting systematic reviews and meta-analyses of studies that evaluate healthcare interventions: explanation and elaboration. BMJ (Clinical research ed.). 2009;339:b2700

14. Shamseer L, Moher D, Clarke M, Ghersi D, Liberati A, Petticrew M, Shekelle P, Stewart LA. Preferred reporting items for systematic review and metaanalysis protocols (PRISMA-P) 2015: elaboration and explanation. BMJ (Clinical research ed.). 2015;349:97647.

15. Higgins JPT, Green S (editors): Cochrane Handbook for Systematic Reviews of Interventions Version 5.1.0 [updated March 2011]; 2011.

16. Coleman BD, Khan KM, Maffulli N, Cook JL, Wark JD. Studies of surgical outcome after patellar tendinopathy: clinical significance of methodological deficiencies and guidelines for future studies. Victorian Institute of Sport Tendon Study Group. Scand J Med Sci Sports. 2000;10:2-11.

17. Morris BJ, Unger RZ, Archer KR, Mathis SL, Perdue AM, Obremskey WT. Risk factors of infection after ORIF of bicondylar tibial plateau fractures. J Orthop Trauma. 2013;27:e196-200.

18. Colman M, Wright A, Gruen G, Siska P, Pape H, Tarkin I. Prolonged operative time increases infection rate in tibial plateau fractures. Injury. 2013;44:249-52.

19. Lin S, Mauffrey C, Hammerberg EM, Stahel PF, Hak DJ. Surgical site infection after open reduction and internal fixation of tibial plateau fractures. European journal of orthopaedic surgery \& traumatology: orthopédie traumatologie. 2014;24:797-803.

20. Kandemir U, Maclean J. Surgical approaches for tibial plateau fractures. The journal of knee surgery. 2014;27:21-9.

21. Lauper N, Hoffmeyer P, Suva D. Fractures de la région du genou chez la personne agée: prise en charge et evolution. Revue médicale suisse. 2012;8:2434-7.

22. Tejwani NC, Hak DJ, Finkemeier CG, Wolinsky PR. High-energy proximal tibial fractures: treatment options and decision making. Instr Course Lect. 2006;55:367-79

23. Schenker ML, Mauck RL, Ahn J, Mehta S. Pathogenesis and prevention of posttraumatic osteoarthritis after intra-articular fracture. The Journal of the American Academy of Orthopaedic Surgeons. 2014;22:20-8.

24. Manidakis N, Dosani A, Dimitriou R, Stengel D, Matthews S, Giannoudis P. Tibial plateau fractures: functional outcome and incidence of osteoarthritis in 125 cases. Int Orthop. 2010;34:565-70.

25. Bachoura A, Guitton TG, Smith RM, Vrahas MS, Zurakowski D, Ring D. Infirmity and injury complexity are risk factors for surgical-site infection after operative fracture care. Clin Orthop Relat Res. 2011:469:2621-30.

26. Castillo RC, Bosse MJ, Mackenzie EJ, Patterson BM. Impact of smoking on fracture healing and risk of complications in limb-threatening open tibia fractures. J Orthop Trauma. 2005;19:151-7.

27. Bullinger M. German translation and psychometric testing of the SF-36 health survey: preliminary results from the IQOLA project. International quality of life assessment. Social science \& medicine (1982). 1995:41:1359-66.

28. Roos EM, Lohmander LS. The knee injury and osteoarthritis outcome score (KOOS): from joint injury to osteoarthritis. Health Qual Life Outcomes. 2003;1:64

29. Babis GC, Evangelopoulos DS, Kontovazenitis P, Nikolopoulos K, Soucacos PN. High energy tibial plateau fractures treated with hybrid external fixation. J Orthop Surg Res. 2011;6:35.

30. Barei DP, Nork SE, Mills WJ, Coles CP, Henley MB, Benirschke SK. Functional outcomes of severe bicondylar tibial plateau fractures treated with dual incisions and medial and lateral plates. J Bone Joint Surg Am. 2006;88:1713-21.

31. Barei DP, Nork SE, Mills WJ, Henley MB, Benirschke SK. Complications associated with internal fixation of high-energy bicondylar tibial plateau fractures utilizing a two-incision technique. J Orthop Trauma. 2004;18:649-57.

32. Berber R, Lewis CP, Copas D, Forward DP, Moran CG. Postero-medial approach for complex tibial plateau injuries with a postero-medial or postero-lateral shear fragment. Injury. 2014;45:757-65.
33. Biggi F, Di Fabio S, D'Antimo C, Trevisani S. Tibial plateau fractures: internal fixation with locking plates and the MIPO technique. Injury. 2010;41:1178-82

34. Bucholz RW, Carlton A, Holmes R. Interporous hydroxyapatite as a bone graft substitute in tibial plateau fractures. Clin Orthop Relat Res. 1989:53-62.

35. Chakraverty JK, Weaver MJ, Smith RM, Vrahas MS. Surgical management of tibial tubercle fractures in association with tibial plateau fractures fixed by direct wiring to a locking plate. J Orthop Trauma. 2009;23:221-5.

36. Cole PA, Zlowodzki M, Kregor PJ. Treatment of proximal tibia fractures using the less invasive stabilization system: surgical experience and early clinical results in 77 fractures. J Orthop Trauma. 2004;18:528-35.

37. Conserva V, Vicenti G, Allegretti G, Filipponi M, Monno A, Picca G, Moretti B. Retrospective review of tibial plateau fractures treated by two methods without staging. Injury. 2015:46:1951-6.

38. Dall'oca C, Maluta T, Lavini F, Bondi M, Micheloni GM, Bartolozzi P. Tibial plateau fractures: compared outcomes between ARIF and ORIF. Strategies in trauma and limb reconstruction (Online). 2012;7:163-75.

39. Egol KA, Tejwani NC, Capla EL, Wolinsky PL, Koval KJ. Staged management of high-energy proximal tibia fractures (OTA types 41): the results of a prospective, standardized protocol. J Orthop Trauma. 2005;19:448-55. discussion 456

40. Engelbrecht E, Siegel A. Palacosunterfütterung und alloplastischer Gelenkersatz bei Tibiakopfbrüchen. Archiv für orthopädische und Unfall-Chirurgie. 1972;74:165-74.

41. Haidukewych G, Sems SA, Huebner D, Horwitz D, Levy B. Results of polyaxial locked-plate fixation of periarticular fractures of the knee. J Bone Joint Surg Am. 2007;89:614-20

42. Hutson JJ, Zych GA. Infections in periarticular fractures of the lower extremity treated with tensioned wire hybrid fixators. J Orthop Trauma. 1998:12:214-8.

43. Jansen H, Frey SP, Doht S, Fehske K, Meffert RH. Medium-term results after complex intra-articular fractures of the tibial plateau. Journal of orthopaedic science: official journal of the Japanese Orthopaedic Association. 2013;18: $569-77$.

44. Khatri K, Lakhotia D, Sharma V, Kiran Kumar GN, Sharma G, Farooque K. Functional evaluation in high energy (Schatzker type $V$ and type VI) Tibial plateau fractures treated by open reduction and internal fixation. International Scholarly Research Notices. 2014;2014:1-8.

45. Neogi DS, Trikha V, Mishra KK, Bandekar SM, Yadav CS. Comparative study of single lateral locked plating versus double plating in type $\mathrm{C}$ bicondylar tibial plateau fractures. Indian journal of orthopaedics. 2015:49:193-8.

46. Ozkaya U, Parmaksizoglu AS. Dual locked plating of unstable bicondylar tibial plateau fractures. Injury. 2015;46(Suppl 2):S9-13.

47. Pun TB, Krishnamoorthy VP, Poonnoose PM, Oommen AT, Korula RJ Outcome of Schatzker type $\mathrm{V}$ and $\mathrm{VI}$ tibial plateau fractures. Indian journal of orthopaedics. 2014:48:35-41.

48. Rademakers MV, Kerkhoffs GMMJ, Sierevelt IN, Raaymakers ELFB, Marti RK. Operative treatment of 109 tibial plateau fractures: five- to 27-year follow-up results. J Orthop Trauma. 2007;21:5-10.

49. Sales JG, Soleymaopour J, Ansari M, Afaghi F, Goldust M. Treatment results of bicondylar tibial fractures using hybrid external fixator. Pakistan journal of biological sciences: PJBS. 2013;16:491-5.

50. Stannard JP, Finkemeier CG, Lee J, Kregor PJ. Utilization of the less-invasive stabilization system internal fixator for open fractures of the proximal tibia: a multi-center evaluation. Indian journal of orthopaedics. 2008;42:426-30.

51. Stannard JP, Wilson TC, Volgas DA, Alonso JE. Fracture stabilization of proximal tibial fractures with the proximal tibial LISS: early experience in Birmingham, Alabama (USA). Injury. 2003;34(Suppl 1):A36-42.

52. EP S, Westrich GH, Rana AJ, Kapoor K, Helfet DL. Operative treatment of tibial plateau fractures in patients older than 55 years. Clin Orthop Relat Res. 2004:240-8.

53. Wagner HE, Jakob RP, Zur Problematik d. Plattenosteosynthese bei den bikondylären Tibiakopffrakturen. Unfallchirurg. 1986;89:304-11.

54. Weaver MJ, Harris MB, Strom AC, Smith RM, Lhowe D, Zurakowski D, Vrahas MS. Fracture pattern and fixation type related to loss of reduction in bicondylar tibial plateau fractures. Injury. 2012;43:864-9.

55. Young MJ, Barrack RL. Complications of internal fixation of tibial plateau fractures. Orthop Rev. 1994;23:149-54.

56. Zhai Q, Hu C, Luo C. Multi-plate reconstruction for severe bicondylar tibial plateau fractures of young adults. Int Orthop. 2014;38:1031-5.

57. Zhang Y, Fan D, Ma B, Sun S. Treatment of complicated tibial plateau fractures with dual plating via a 2-incision technique. Orthopedics. 2012;35: e359-64. 